\title{
Context-dependency of enemy impact on plant communities in a changing world
}

2

$$
\text { Anne Kempel }{ }^{1 *} \text {, Harald Auge }{ }^{2} \& \text { Eric Allan }{ }^{1}
$$

3

$4{ }^{1}$ Institute of Plant Sciences, Altenbergrain 21, 3013 Bern, Switzerland

$5{ }^{2}$ Helmholtz-Centre for Environmental Research - UFZ, Theodor-Lieser-Strasse 4, 06120 Halle (Saale),

6 Germany

$7 \quad *$ Corresponding author: anne.kempel@ips.unibe.ch

8

9 Abstract

10 Global environmental change is strongly altering biodiversity and ecosystem functioning. Antagonistic

11 biotic interactions affect the diversity and functioning of plant communities but are notoriously 12 context dependent and are therefore likely to be altered by global change drivers. Global change can 13 directly affect biotic interactions and can also indirectly alter the abundance, diversity and 14 composition of plant enemy communities, via changes to plant productivity, diversity and functional 15 composition. Changes in the enemy community feedback to alter the plant community. However, we 16 lack predictions for how different global change drivers may alter enemy communities and their 17 impact on plant communities. In this review we summarize current knowledge on the impact of 18 invertebrate herbivores and fungal pathogens on plant productivity, diversity and community 19 composition, and outline theory and expectations on how important global change drivers - nitrogen 20 enrichment, warming and elevated $\mathrm{CO}^{2}$, as well as the loss of plant and insect diversity, may affect the 21 impact of plant-enemies on plant communities.

22

23 Keywords: Global change, plant-herbivore interactions, plant-pathogen interactions, coexistence, 24 antagonistic biotic interactions 
 \\ Introduction}

28 A major current challenge is to predict how biodiversity and ecosystem functioning will respond to ongoing environmental change. One key knowledge gap limiting our predictive ability, is how changes

30 in antagonistic biotic interactions will alter the diversity, composition and functioning of plant 31 communities. The few studies on effects of global change that explicitly considered antagonistic interactions among species indicate, however, that such interactions may profoundly affect, and even reverse, ecosystem responses (Suttle et al. 2007; Post \& Pedersen 2008). Today, it is widely appreciated that vertebrate herbivores can have strong impacts on plant communities with large effects on plant primary production, species composition, plant diversity, or ecosystem processes (e.g.

Duffy et al. 2003, Borer et al. 2014b, Jia et al. 2018). However, for the vast majority of consumer groups, such as invertebrate herbivores and plant pathogens, we still lack a general understanding of their contribution to biodiversity and ecosystem functioning (Mordecai 2011; Myers \& Sarfraz 2017; Jia et al. 2018), as only a few studies have compared the impacts of the different enemy groups or tested for interactions between them. Moreover, a large body of theoretical and empirical work suggests that biotic interactions vary substantially in space and time. Hence, the impact of plant enemies on plant communities might differ depending on many abiotic and biotic factors (e.g. Dobzhansky 1950, Ford et al. 2014). However, there is no consensus on the key factors driving variation in impact (Maron et al. 2014a; Jia et al. 2018), which is essential to predict effects of global change on our ecosystems.

In this review we summarize recent advances in our understanding of the impact of invertebrate herbivores and fungal pathogens on different aspects of plant communities: plant diversity, plant community composition and plant productivity, and highlight open questions and knowledge gaps. Moreover, we outline the ecological theory on how variation in environmental conditions will affect plant-enemy interactions, and use this to develop predictions for how important direct global change drivers - nitrogen enrichment, warming, and increased $\mathrm{CO}_{2}$, and indirect global change drivers such as plant and insect diversity loss, may affect the impact of plant-enemies on plant communities. 
54 General impact of plant enemies on plant communities

Plant enemies can alter several aspects of plant community structure (Crawley 1997; Mordecai 2011;

Kempel et al. 2015; Jia et al. 2018). Enemies alter primary productivity by consuming or preventing

the accumulation of plant biomass. However, they will only do this if they are not limited by predation

(Fretwell 1987; Oksanen \& Oksanen 2000). Herbivores and plant pathogens can also be important drivers of coexistence between plant species and can therefore affect plant diversity (Holt 1977; Chesson 2000). Even if enemies do not alter diversity, they frequently change competitive interactions between plant species or sometimes even directly exclude plant species from communities, and can therefore alter the composition of plant communities even if they do not alter diversity (Crawley 1997). We discuss the impact of plant enemies on these three aspects of plant communities.

\section{Impact of enemies in plant productivity}

Plants are consumed by a variety of organisms that feed in different ways and on different types of plant tissue, above- or belowground. These enemies can be very restricted in their diet or can be very generalist. Despite the high diversity and foraging strategies of plant enemies, studies aiming to understand their role in determining plant community dynamics have mainly focused on vertebrate herbivores (Olff \& Ritchie 1998; Hillebrand et al. 2007). Their effect on plant productivity has intrigued ecologists for many decades and early theory suggested that herbivores were typically top-down regulated and therefore unable to affect plant biomass (Hairston et al. 1960). However, today there is ample evidence for widespread, top-down effects of vertebrate herbivores on plant communities (e.g. Borer et al. 2014b, Terborgh 2015, Jia et al. 2018). It has often been assumed that invertebrate herbivores and pathogens are too small or specialised to have large effects (Olff \& Ritchie 1998). Invertebrate herbivores are also frequently assumed to be regulated by predators and therefore unable to exert strong top down control on plant production. However, several individual studies have now shown that invertebrate herbivores and fungal pathogens can affect plant productivity (e.g. 
Buschmann et al. 2005; Van Der Heijden et al. 2008; Allan et al. 2010; Allan \& Crawley 2011; Mordecai

80 2011; Seabloom et al. 2018). Nevertheless, effects are often highly variable between studies. While one meta-analysis on insecticide experiments in grassland found an increase in primary production when insects where removed (Coupe \& Cahill Jr 2003), a recent meta-analysis showed no consistent top-down effect of aboveground invertebrate herbivores on plant biomass (Jia et al. 2018). For other groups, such as belowground invertebrates, molluscs or fungal pathogens, the impact on plant communities is even less well known, although strong effects have been shown in some studies (e.g. Stein et al. 2010; Allan \& Crawley 2011). It is therefore important to develop predictions about when invertebrate herbivores and pathogens could affect plant productivity.

\section{Impact of enemies on plant diversity}

90 Plant enemies frequently alter competitive interactions between plants and can therefore alter the 91 diversity of plant species in a community (Holt 1977; Chesson 2000; Bever et al. 2015). Enemies can promote coexistence if they preferentially attack the more abundant plant species within a community (Carson and Root 2000, Petermann et al. 2008, Bever et al. 2015, Pacala \& Crawley 1992).

This can arise either through a correlation between palatability and dominance or a correlation between sensitivity of plants to attack and dominance (Pacala and Crawley 1992). If enemy attack rate declines with decreasing frequency of the host plant (negative-frequency dependence), enemies can drive niche differences between plant species and therefore stabilise plant coexistence (e.g. Chesson 2000). If the attack rate by specialist enemies declines non-linearly with host abundance, e.g. if rare hosts are difficult to locate and therefore escape attack, then specialists will stabilise coexistence.

100 However, generalist enemies can theoretically also have stabilizing effects on plant communities if

101 they switch host or food plant species to disproportionally consume whichever species is most 102 abundant (Murdoch 1969; Chase et al. 2002; Ishii \& Crawley 2011). Plant enemies can also promote 103 diversity by reducing average fitness differences between plant species. This also requires a trade-off 104 between dominance and palatability, e.g. if there is a trade-off between the growth of plants in a 
105 resource rich environment and their defense against enemies, assuming that defense is costly and 106 constrains investment in other important traits (Coley et al. 1985; Herms \& Mattson 1992; Kempel et 107 al. 2011). In this case enemies promote coexistence by reducing the competitive ability (fitness) of 108 more vigorously growing plant species, which can equalize fitness between dominant and less 109 dominant plant species, even if enemy attack is not frequency dependent. Such equalizing effects have 110 mainly been attributed to generalist enemies, however specialist enemies can theoretically also 111 equalize fitness differences between plant species if they specialize predominantly on fast growing 112 but poorly defended plant species (Chesson 2000; Chase et al. 2002).

113 Empirical studies excluding plant enemies have found highly variable effects on plant diversity (Olff \& 114 Ritchie 1998; Proulx \& Mazumder 1998; Hillebrand et al. 2007; Allan et al. 2010; Allan \& Crawley 2011;

115 Korell et al. 2017). While large vertebrate herbivores were found to slightly promote grassland 116 diversity in a recent meta-analysis (evenness, Jia et al. 2018), effects of invertebrates were more 117 variable (Stein et al. 2010; Jia et al. 2018). Evidence from the tropics (Mangan et al. 2010; Bagchi et al. 118 2014) and also from plant-soil feedback experiments in temperate grasslands (Petermann et al. 2008) 119 suggest that soil-borne plant pathogens are able to maintain high levels of diversity through Janzen120 Connell effects.

\section{Effects of plant enemies on plant species composition}

123 Plant enemies may also alter plant species composition without changing diversity. Plant enemies can

124 reduce the competitive ability of certain species, leading to competitive release for other plants and 125 in some cases the exclusion of the preferred species and its replacement by other less preferred 126 species (Crawley 1997). For instance, insects strongly changed species composition by increasing 127 seedling mortality for certain species, without altering diversity in tropical rainforest (Bagchi et al. 128 2014). In general, plant enemies might change plant functional composition by preferentially attacking 129 faster growing, less defended plant species rather than slower growing, and more defended ones (e.g. 130 Lind et al. 2013; Kempel et al. 2015; Cappelli et al. 2019). Recent work on fungal pathogens in grassland 
131 has shown that plant species with a fast growth strategy are more likely to be infested by pathogens

132 than species with a slow growth strategy (Cappelli et al. 2019). Communities consisting of fast growing 133 species were also shown to be more strongly impacted by fungal pathogens (they lost more biomass)

134 than communities consisting of slower growing species (Cappelli et al. 2019), indicating that fungal

135 pathogens consistently shift plant communities towards more slow growing, better defended species.

136 Similarly, invertebrates have been shown to drive plant community composition (e.g. Allan \& Crawley

137 2011; Kempel et al. 2015), however effects depended on the group of enemies excluded, or the 138 preference of herbivores, and were not necessarily linked to a fast or slow growth strategy of plants 139 (Maron et al. 2014a; Korell et al. 2017).

\section{Context-dependency of enemy impact on plant communities}

142 The outcome of biotic interactions are notoriously context-dependent (Chamberlain et al. 2014; 143 Maron et al. 2014a; Kempel et al. 2019) and the impact of enemies on plant communities might differ 144 depending on many abiotic and biotic factors. In general, enemy impact can be driven by changes in 145 the enemy and plant community. Changes in enemy abundance, diversity and per capita feeding rate 146 will alter the impact of enemies on plant productivity, while changes in enemy diversity and degree of 147 specialisation are likely to determine the impact of enemies on plant diversity and species composition

148 (Fig. 1). Global change can alter all of these characteristics of the enemy community. Global change 149 drivers might directly alter per capita feeding rate and/or they might indirectly alter enemy 150 communities by changing the plant community. For instance, increases in plant productivity might 151 increase enemy abundance (Haddad et al. 2000), increases in plant diversity are expected to increase 152 enemy diversity (Scherber et al. 2010) and perhaps the proportion of specialists (Schemske et al. 153 2009), while a shift to fast growing plant species might increase the abundance of generalists. 154 Characteristics of the plant community may also determine the impact that enemies can have on the community, for instance enemies may have a larger impact in communities dominated by a few plant species (resource concentration hypothesis) or in communities dominated by more palatable fast 
157 growing species. Global change drivers can therefore alter the feedbacks between enemy and plant 158 communities and thereby drive changes in biotic interactions. Understanding how they do so is one 159 of the greatest current ecological challenges and would provide essential information for a range of 160 pressing problems, from improving global change forecasts to predicting the efficacy of weed biocontrol (HilleRisLambers et al. 2012; Louthan et al. 2015). In the following, we provide a framework for how important global change drivers, namely nitrogen enrichment, climate warming and an increase in atmospheric carbon dioxide might modify the impact of plant enemies on plant productivity, diversity and plant functional composition. In addition, we discuss the consequences of the ongoing plant diversity loss and the massive insect die off for plant-enemy interactions.

Effects of nitrogen enrichment on plant-enemy impact on plant communities

Nitrogen enrichment is a key global change driver altering biodiversity and ecosystem functioning. It typically causes a loss of plant diversity (Stevens et al. 2004) and increases plant biomass production (Crawley et al. 2005) and tissue nitrogen concentrations (Wardle et al. 2012) and leads to a shift towards faster growing plant species (Lavorel \& Grigulis 2012). It is likely to alter enemy impact on plant communities through several of these direct and indirect effects. Theory predicts that low resource environments select for slow growing species with high levels of defence whereas high resource environments select for fast growing, less defended species (Coley et al. 1985). Similarly, the

175 nitrogen disease hypotheses states that plants growing in nitrogen rich environments are more 176 attractive to enemies due to a higher nitrogen concentration in their tissue (Dordas 2008).

177 Consequently, fast growing, more acquisitive species, and species growing in nitrogen rich conditions,

178 should suffer higher levels of herbivory or pathogen infection than species with a conservative 179 strategy (Fine et al. 2004; Kempel et al. 2011; Seabloom et al. 2018). However, species with acquisitive traits or with access to more soil resources might be more tolerant of enemy attack, meaning that the actual impact of enemies could be lower, despite higher infestation (Cronin et al. 2010). In addition, 
183 predicts that in resource rich environments with a high primary production, natural enemies of

184 herbivores (predators) should control herbivore populations. This might lead to no change in enemy

185 impact on plant productivity, if all the additional plant productivity is transferred to predators,

186 however so far the pattern has been only shown for vertebrates and not for invertebrate herbivores

187 (Schädler et al. 2003).

188 The evidence for changes in herbivore and pathogen impact with productivity and fertility is mixed.

189 Herbivore biomass has been shown to increase with increases in plant productivity (Chase et al. 2000;

190 Lind et al. 2017, Kempel et al. in prep), however, herbivore impact has sometimes been shown to be

191 unaffected or even to decrease with increasing productivity (Chase et al. 2000; Coupe \& Cahill Jr 2003).

192 Results from a recent meta-analysis were surprisingly uninformative for understanding patterns in the

193 strength of herbivore impact among systems differing in net primary production (indicator of soil

194 fertility, Jia et al. 2018). Yet, whether the impact of plant enemies increases with increasing soil fertility

195 is not fully resolved.

196 Expectations. (1) Nitrogen enrichment affects impact of enemies on plant productivity.

197 The nitrogen disease hypothesis suggests that the impact of enemies on plant productivity is higher in resource rich environments, because a higher nitrogen content in leaves makes plants more attractive.

199 The resource availability hypothesis further predicts that fast-growing plant species, which are

200 favoured by nitrogen enrichment, are less defended and should therefore suffer more from enemy 201 attack. Moreover, a high soil fertility may reduce the presence of beneficial soil microbes, which have 202 been shown to provide resistance against herbivores to plants (Pozo \& Azcón-Aguilar 2007; Koricheva 203 et al. 2009; Kempel et al. 2010), further increasing enemy impact. While plant and also herbivore 204 biomass have been shown to increase with soil fertility, impact has not. This might suggest that fast205 growing plant species are more tolerant and compensate leaf loss, or that top-down control of 206 herbivores by predators might be stronger at high soil fertility. It is therefore not clear how the impact 207 of enemies on plant productivity will change with nitrogen enrichment. 
208 (2) Nitrogen enrichment affects impact of enemies on plant diversity. At high soil fertility plant communities are dominated by fast growing plant species, which usually reduces plant diversity. We

210 therefore expect that the impact of enemies on plant diversity is stronger at high soil fertility, as plant

211 enemies reduce plant dominance of good light competitors, equalizing fitness. (Hillebrand et al. 2007).

212 The mechanisms behind this might be that in resource rich environments dominant species are less

213 defended (growth-defense trade-off), or that good light competitors are tall and are therefore more

214 likely to be removed by grazers. The latter would mainly apply to vertebrates.

215 (3) Nitrogen enrichment affects impact of enemies on plant functional composition. We expect that

216 the impact of enemies on plant functional composition is stronger at high soil fertility, because fast-

217 growing but less defended plant species from fertile environments are held in check by generalist

218 enemies, allowing slower growing but more defended species to persist. Excluding enemies from

219 fertile communities would result in a loss of slower growing species, shifting functional composition

220 towards even faster growing species. In resource poor conditions however, slower growing species

221 with high levels of defences are favoured as they are usually better at competing for soil resources

222 than fast growing, poorly defended plant species (Lind et al. 2013). Excluding enemies in resource

223 poor environments would therefore have minor effects on plant functional composition, as fast

224 growing species will still be outcompeted by the slow growing species and are therefore unlikely to be able to increase.

\section{Effects of temperature on plant-enemy impact on plant communities}

228 Increases in temperature following global climate change will not only affect plant growth directly but are also likely to change plant communities indirectly by modifying their pathogen and herbivore

230 communities. The current prediction for herbivores and pathogens is that their impact on plants will 231 increase because warmer temperatures tend to increase insect and pathogen metabolic rates (Brown 232 et al. 2004), accelerating their development and reproduction (Coakley et al. 1999; Malmström \& 233 Raffa 2000; Roy et al. 2004). However, this will only occur if precipitation remains high and increases 
234 in temperature in arid environments would be expected to reduce herbivore and pathogen attack.

235 Existing environmental gradients in climate can be used to predict changes in plant enemy impact with

236 changes in temperature and precipitation. For example, it has long been predicted that the

237 importance of biotic interactions is strongest at low latitudes and declines towards the poles

238 (Dobzhansky 1950, Schemske et al. 2009), which would suggest a potential increase in biotic

239 interactions with increased temperature. However, the mechanisms driving this emerge over long

240 time scales and are typically thought to be that a more predictable and benign climate in the tropics

241 leads to stronger and more specialized biotic interactions, promoting coevolution and speciation

242 (Coley and Kursar 2014), and further diversification of species (Vermeij 2005, Schemske et al. 2009).

243 Particularly, a stronger impact of plant herbivores and soil fungal pathogens is suggested to be a major

244 mechanism for the maintenance of high tropical diversity (Janzen 1970, Connell 1971, Mangan et al.

245 2010, Bagchi et al. 2014). It is therefore unlikely that current changes in temperature and precipitation

246 will lead to an increase in the strength of biotic interactions. Further, evidence for the so-called biotic

247 interaction hypothesis from studies comparing herbivory rates across latitudes is mixed (Schemske et

248 al. 2009, Moles et al. 2011, Anstett et al. 2016, Jia et al. 2018). Similarly, evidence for a higher degree

249 of specialist herbivores (Dyer et al. 2007, Novotny et al. 2007, Slove and Janz 2010), and plant defense

250 (Moles et al. 2011) in the tropics is conflicting, so that the generality of the biotic interaction

251 hypothesis has been questioned (Anstett et al. 2016, Moles and Ollerton 2016, Jia et al. 2018).

252 Latitudinal gradients in the intensity of biotic interactions may not predict changes with climate

253 change but altitudinal gradients are frequently used as proxies of future climate change (Sundqvist et

254 al. 2013; Alexander et al. 2015). They are ideal to address the question how abiotic factors drive

255 variation in species interactions, as they occur over much smaller scales and are less confounded by

256 historical or macro-evolutionary processes, such as dispersal limitation, or regional variation in day

257 length or inter-annual climatic variations (Moreira et al. 2018). Accordingly, several studies have

258 shown that herbivore pressure is higher at lower elevations, which are warmer and less variable

259 climatically with reduced wind and sun exposure, (Rasmann et al. 2014; Galmán et al. 2018). This 
260 should result in decreased plant defense at high elevations and a higher proportion of generalist

261 consumers, however, recent studies reported inconsistent patterns between elevation and herbivory,

262 questioning the generality of previews findings (Galmán et al. 2018, Moreira et al. 2018). Interactions

263 between plants and fungi are also likely to vary with elevation as fungal communities are sensitive to

264 changes in temperature and precipitation (Bryant et al. 2008, Vacher et al. 2008, McGuire et al. 2012,

265 Sundqvist et al. 2013). Previous studies have shown that soil microbial diversity (Fierer et al. 2011,

266 Singh et al. 2012), community structure (Margesin et al. 2009, Pellissier et al. 2014) and abundance

267 (Djukic et al. 2010) vary along several elevational gradients. However, studies rarely assess impact of 268 enemies on plant communities or functioning along altitudinal gradients, i.e. by using exclusions

269 (Sundqvist et al. 2013). Thus, whether the impact of invertebrate herbivores and fungal pathogens on

270 ecosystems increases with climate warming is not fully resolved.

271 Expectations. (4) Temperature affects impact of enemies on plant productivity. Plant productivity

272 increases with warmer temperatures and higher precipitation, and this would be predicted to increase

273 enemy abundance and therefore enemy impact on plant productivity. Evidence for this comes from

274 increased rates of herbivory in the tropics and at low elevations, and an increase in pathogen and

275 herbivore attack also in warming experiments (Roy et al. 2004; Liu et al. 2011; Gillespie et al. 2013;

276 Birkemoe et al. 2016). However, other warming experiments found no change (Richardson et al. 2002)

277 or even a decrease (Barrio et al. 2016) in herbivory, suggesting that species-specific changes in plant

278 quality (leaf nutrients, defensive compounds) also determine enemy attack.

279 Predictions for how enemy impact on plant diversity and composition will change with alterations in

280 the climate are not so clear, as only few studies have interactively manipulated temperature and

281 enemy abundance (but see Suttle et al. 2007; Lemoine et al. 2017).

282

283 Effects of elevated atmospheric carbon dioxide on enemy impact on plant communities

284 Another key element of anthropogenic climate change is an increase in atmospheric $\mathrm{CO}_{2}$ levels. The 285 drastic rise in $\mathrm{CO}_{2}$ is likely to not only affect plant growth but also their interactions with their enemies. 
286 Experiments have shown that elevated $\mathrm{CO}_{2}$ has large impacts on plant physiology, generally enhancing

287 plant growth and increasing the C:N ratio in plants (Robinson et al. 2012; Sardans et al. 2012).

288 Moreover, it is likely that an increased C supply to plants leads to an increase in C-based secondary

289 and structural compounds, further decreasing plant quality (Stiling \& Cornelissen 2007; Robinson et

290 al. 2012). As invertebrate herbivores and also pathogens are largely $\mathrm{N}$-limited an increase in C:N ratios

291 is likely to lead to lower food quality. Results from meta-analysis suggest that while chewing

292 herbivores respond in the short term with increased food consumption to compensate for the lower

293 nutritional quality, they also grow more slowly and have a longer development time, which increases

294 exposure to enemies all of which reduce herbivore abundance under elevated $\mathrm{CO}_{2}(\mathrm{Stiling} \&$

295 Cornelissen 2007; Robinson et al. 2012). Phloem feeding insects instead tend to respond positively to

296 elevated $\mathrm{CO}_{2}$ (Robinson et al. 2012). In addition, the effect of elevated $\mathrm{CO}_{2}$ on plant pathogen disease

297 might be different for plants with a $C_{4}$ metabolism. $C_{4}$ plants are suggested to be less water stressed

298 under elevated $\mathrm{CO}_{2}$, which will increase pathogen disease severity (Thompson \& Drake 1994; Mitchell

299 et al. 2003). Concordantly, pathogen load has also been shown to increase under elevated $\mathrm{CO}_{2}$ for

300 certain species (Coakley et al. 1999; Mitchell et al. 2003; Lake \& Wade 2009).

301 Results from global change experiments further suggests that plant community composition might change in response to $\mathrm{CO} 2$ enrichment. Legumes have been shown to increase in response to elevated CO2, whereas C3 and C4 grasses are less responsive (Jablonski et al. 2002). As $C_{3}$ and $C_{4}$ plants respond to elevated $\mathrm{CO}_{2}$ with an increase in the $\mathrm{C}: \mathrm{N}$ ratio, it is likely that enemy preference may shifts towards $\mathrm{N}$-fixing plant species, counteracting enhanced growth in these functional groups. Thus, plant community shifts that are predicted to occur under elevated $\mathrm{CO} 2$ might be modified by variation in enemy impact driven by changes in host preference. However, current knowledge on how plant enemy affect plant functional composition under elevated $\mathrm{CO}_{2}$ is limited.

309 Expectations. (5) Elevated $\mathrm{CO}_{2}$ affects impact of enemies on plant productivity. An increase in

310 atmospheric carbon dioxide is expected to decrease plant quality via an increase in the C:N ratio and 311 carbon-based secondary compounds. We therefore expect that enemy abundance and hence impact 
312 will decrease. However, for pathogens effects might be different, depending on a plants

313 photosynthetic pathway: for $\mathrm{C}_{4}$ plants pathogen load might increase under elevated $\mathrm{CO}_{2}$, as their

314 water stress decreases which can increase fungal sporulation (Thompson \& Drake 1994).

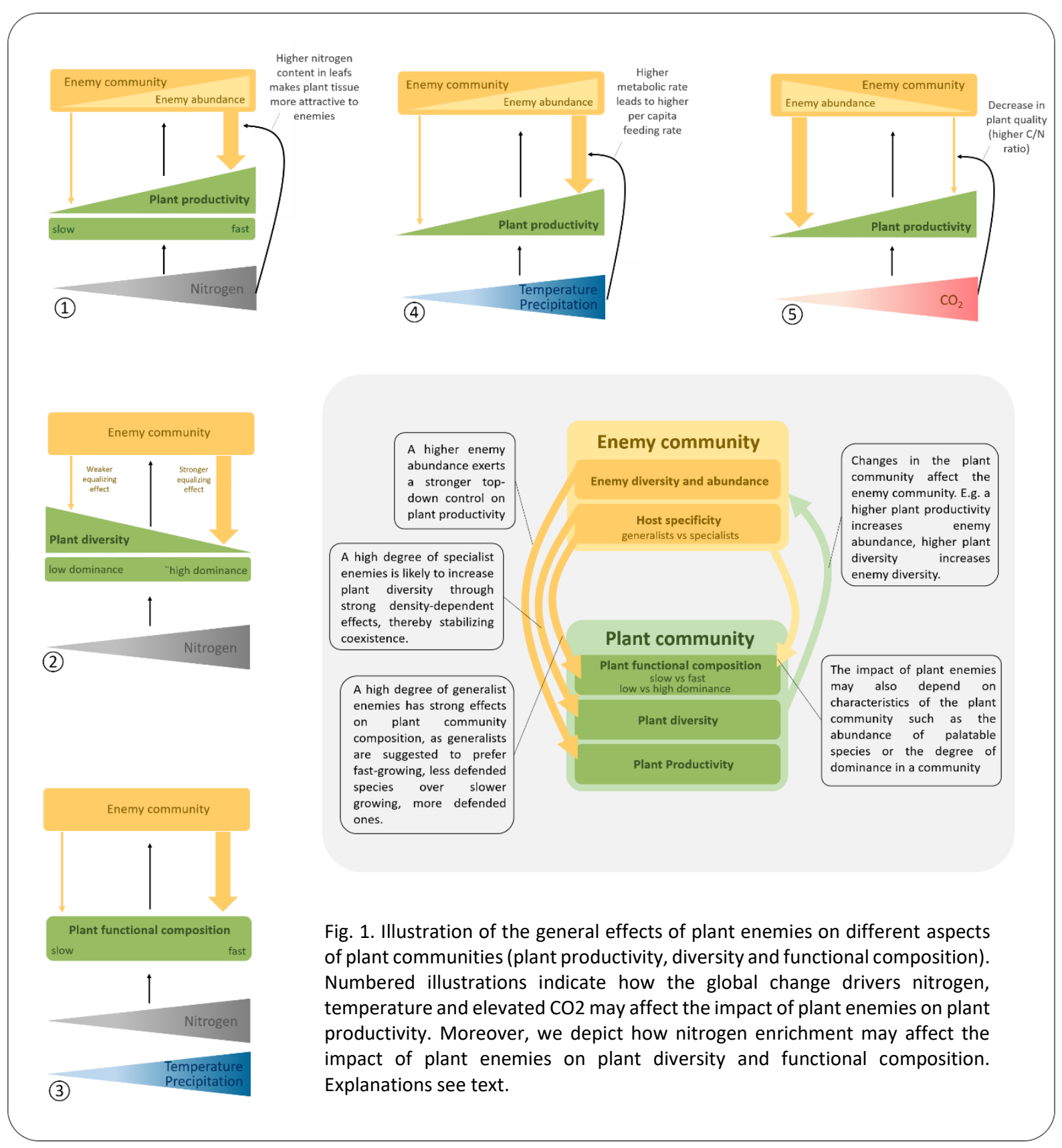

317 Consequences of decline in plant and insect diversity for plant-enemy interactions

318 In addition, to the impacts of nitrogen and climate change, other global change factors such as invasive species or pesticide use may cause declines in plant and insect diversity (Sala et al. 2000; Seibold et al. 
320 2019). A decline in plant diversity is likely to alter the impact that invertebrate herbivores and

321 pathogenic fungi have on plant communities. The idea that plant communities with higher densities

322 of a few species should be more vulnerable to negative effects of specialized pathogens and

323 herbivores, and that communities of high plant diversity harbour a larger community of natural

324 enemies has a long history in ecology (Root 1973, host concentration hypothesis, Pimentel 1961).

325 Indeed, studies manipulating plant species diversity of grassland communities have shown that

326 pathogen attack is generally higher in species poor compared to species rich communities (Mitchell et

327 al. 2002; Maron et al. 2011; Schnitzer et al. 2011; Schnitzer \& Klironomos 2011; Johnson et al. 2013;

328 Rottstock et al. 2014). For herbivores, results from previous studies have been ambiguous, and

329 abundance, diversity and impact of herbivores have also been shown to be highest at high plant

330 diversity (Haddad et al. 2001; Stein et al. 2010; Borer et al. 2012; Loranger et al. 2014; Seabloom et al.

331 2017, but see Koricheva et al. 2000). However, results for specialist insect pests are more consistent

332 and resource concentration effects are commonly observed (Jactel \& Brockerhoff 2007). However,

333 most of the evidence for resource concentration effects comes from experiments in which diversity is

334 manipulated and species compositions are random (e.g. Rottstock et al. 2014) and responses of

335 herbivores and pathogens to real world gradients of diversity are less well known (Halliday \& Rohr

336 2019).

337 Several recent studies have also suggested that insect populations are declining in abundance

338 (Hallmann et al. 2017) and this loss of insect abundance and diversity is likely to have consequences

339 for plant communities. In German grasslands it has been shown that all trophic guilds of insects,

340 including herbivores, have declined in their biomass, abundance and diversity (by 67\%, 78 and $34 \%$

341 respectively) since 2008 (Seibold et al. 2019). The decline has been associated with land-use

342 intensification at the landscape level. Because herbivores are suggested to promote plant coexistence

343 by preferentially attacking fast-growing dominant plant species (equalizing fitness differences), or by

344 exerting frequency dependent effects on their specific host plants (increasing niche differences which

345 are necessary for stable coexistence, Chesson 2000; Bartomeus \& Godoy 2018), a decline in herbivore 
346 abundance and diversity is likely to result in a decline in their diversity-promoting effects. This might

347 have far reaching consequences for plant diversity.

348 Expectations. (6) Plant diversity loss affects impact of enemies on plant productivity. We would

349 expect that the impact of natural enemies on plant productivity increases with plant diversity loss

350 (host concentration hypothesis, diversity-disease hypothesis). However, the effect of plant diversity

351 loss on enemies will also depend on the species that are lost first from the community (Keesing et al.

352 2010): if susceptible or palatable species are lost last, for instance if fast growing species remain

353 following nutrient enrichment, then diversity loss will enhance disease transmission. However, the

354 opposite will occur if resistant species are lost last.

355 (7) Insect decline alters effects on plant diversity. A loss of insect biomass, abundance and diversity

356 is likely to weaken the stabilizing and equalizing effects of herbivores on plant coexistence. This might

357 have far reaching consequences for plant diversity.

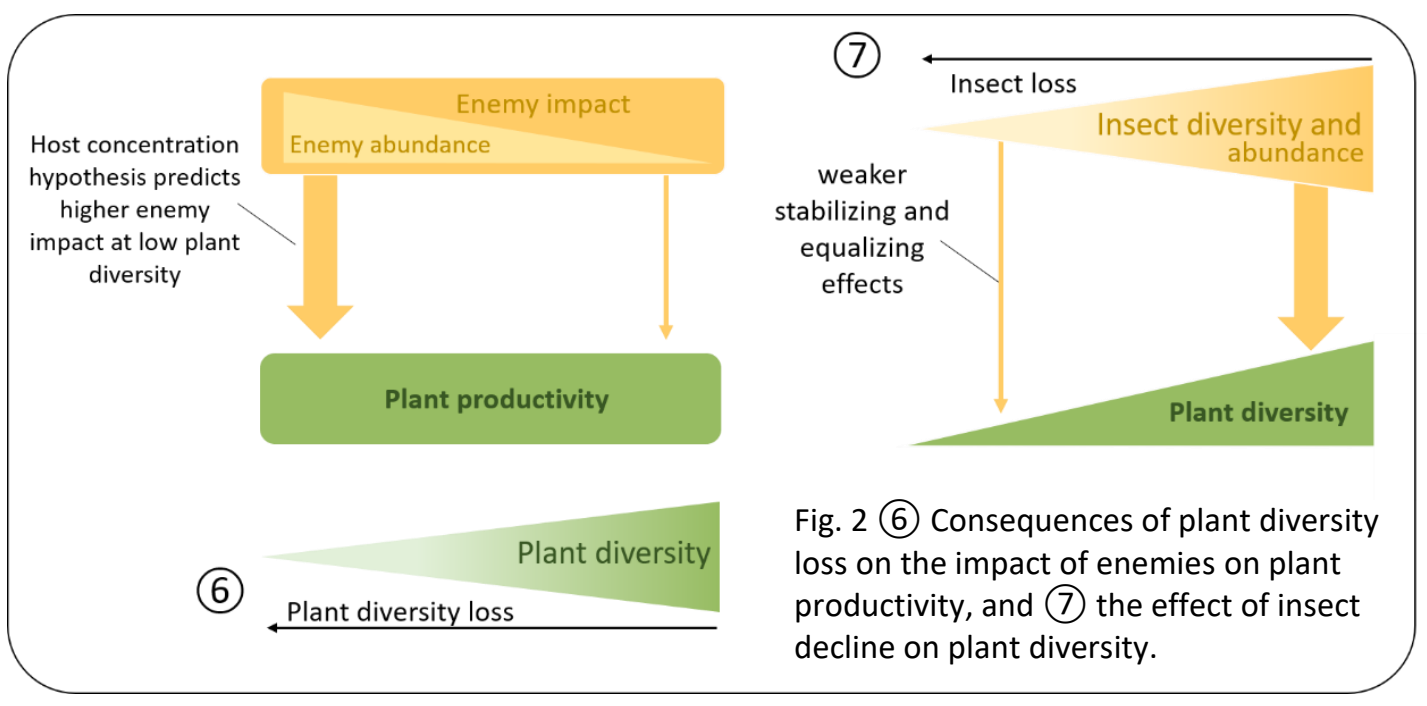

Global change effects on plant-enemy interactions at a population level

361 In addition to the indirect effects taking place at the community level, global change drivers may also

362 strongly affect host plants and their enemies at the individual and population level. For instance, global change may affect host plant populations and enemy populations in parallel, leading to a temporal 
364 mismatch due to changing phenology or spatial mismatch (due to changing geographic ranges, e.g.

365 (Schweiger et al. 2012) of interacting species, which in turn may alter enemy impact. For example range expanding plant species have been shown to move faster than their belowground enemies, leading to enemy release in their new range (e.g van Grunsven et al. 2010; Zuppinger-Dingley et al. 2011), similarly to the hypothesized release of enemies of exotic plant species in their new range (Keane \& Crawley 2002; Maron et al. 2014b). Moreover, interactions of plants with belowground mutualists such as mycorrhizal fungi might be affected by global change drivers such as warming or nitrogen enrichment (Egerton-Warburton et al. 2007), which might also indirectly affect plant-enemy interactions. Thus, global change drivers will not only affect resident plant communities (and their interactions with insects and pathogens), but will also lead to novel species assemblages with different interactions (Tylianakis et al. 2008; Alexander et al. 2015).

\section{Concluding remarks and future avenues}

377 Global environmental change may strongly alter the impact of plant enemies on several aspects of plant communities, and our review revealed several patterns. Results from studies comparing enemy impact along natural environmental gradients suggests that an increase in nitrogen as well as temperature may both lead to an increase in enemy abundance. Whether this will feedback on plant productivity and will increase the impact (loss of biomass due to enemies) of enemies, however, is less clear. Contrarily, elevated $\mathrm{CO}_{2}$ might reduce certain enemy groups via a reduction in plant quality, potentially counteracting nitrogen and temperature effects. However, studies mainly focussed on enemy groups such as lepidopteran caterpillars and the few studies on other enemy groups (e.g. sucking herbivores or fungal pathogens) suggest that responses depend on enemy guild. Nitrogen enrichment and warming might both lead to a shift in the plant functional composition towards more

387 fast growing plant species with a high competitive ability in nutrient rich environments, elevated $\mathrm{CO}_{2}$ 388 might specifically favour $\mathrm{N}$-fixing plant species. In these fast-growing communities plant enemies may be particularly important for the maintenance of plant diversity, as they equalize fitness differences 
390 between plant species by preferentially attacking the dominant, less defended species. Thus, the

391 importance of plant-enemies as diversity-promoting agents might increase with global change. The

392 ongoing decline in insect species, biomass and abundance, including herbivores, might therefore have

393 far-reaching consequences for plant diversity, particularly in a warmer and nutrient richer world as a

394 lower top-down control by enemies might lead to a greater dominance by certain species, potentially

395 leading to competitive exclusion and a loss of plant diversity.

396 In sum, our review revealed several general patterns in how global change affects enemy communities

397 directly and indirectly via changes in the plant community, however it also revealed gaps in our

398 understanding of the context-dependency of plant-enemy interactions (Maron et al. 2014a). The

399 reason for this is that experiments are typically not designed to identify drivers of context-dependence

400 and that large-scale patterns are usually pieced together from data obtained by a variety of methods

401 and protocols (Gurevitch \& Mengersen 2010). Moreover, while effects on enemy communities are

402 well studies, we often have a limited idea of whether such changes also translates into changes in the

403 impact of plant enemies on plant communities, as studies often rely on comparing herbivore or

404 pathogen attack along environmental gradients and rarely measure impact experimentally, i.e. by

405 using exclusion to look at the consequences of herbivory or fungal infection for plant diversity,

406 composition or functioning (Anstett et al. 2016, Burdon et al. 2006, Sundqvist et al. 2013, Louthan et

407 al. 2015). Thus, to predict the consequences of global change on the diversity and functioning of our

408 ecosystems we need to develop a predictive understanding of why and how antagonistic biotic

409 interactions vary in space. Exclusion of different plant enemies along environmental gradients might

410 be one way forward to obtain generality in the impact and context-dependency of plant enemies on

411 the diversity, composition and functioning of plant communities. Moreover, experiments

412 simultaneously manipulating various global change drivers while also excluding enemy groups can

413 inform us about potential changes in plant-enemy impacts on plant communities under global change.

414 Enhancing our knowledge on how antagonistic biotic interactions alter the diversity and functioning 
415 of plant communities, and how their impact depend on abiotic and biotic factors is a pressing priority

416 given current global change scenarios, and the recently observed insect die-off.

417

418

419 


\section{References}

Alexander, J.M., Diez, J.M. \& Levine, J.M. (2015). Novel competitors shape species' responses to climate change. Nature, 525, 515.

Allan, E. \& Crawley, M.J. (2011). Contrasting effects of insect and molluscan herbivores on plant diversity in a long-term field experiment. Ecology Letters, 14, 1246-1253.

Allan, E., van Ruijven, J. \& Crawley, M.J. (2010). Foliar fungal pathogens and grassland biodiversity. Ecology, 91, 2572-2582.

Anstett, D.N., Nunes, K.A., Baskett, C. \& Kotanen, P.M. (2016). Sources of Controversy Surrounding Latitudinal Patterns in Herbivory and Defense. Trends in Ecology \& Evolution, 31, 789-802.

Bagchi, R., Gallery, R.E., Gripenberg, S., Gurr, S.J., Narayan, L., Addis, C.E., et al. (2014). Pathogens and insect herbivores drive rainforest plant diversity and composition. Nature, 506, 85.

Barrio, I.C., Bueno, C.G. \& Hik, D.S. (2016). Warming the tundra: reciprocal responses of invertebrate herbivores and plants. Oikos, 125, 20-28.

Bartomeus, I. \& Godoy, O. (2018). Biotic controls of plant coexistence. Journal of Ecology, $106,1767-1772$.

Bever, J.D., Mangan, S.A. \& Alexander, H.M. (2015). Maintenance of Plant Species Diversity by Pathogens. Annu. Rev. Ecol. Evol. Syst., 46, 305-325.

Birkemoe, T., Bergmann, S., Hasle, T.E. \& Klanderud, K. (2016). Experimental warming increases herbivory by leaf-chewing insects in an alpine plant community. Ecology and Evolution, 6, 6955-6962.

Borer, E.T., Seabloom, E.W., Gruner, D.S., Harpole, W.S., Hillebrand, H., Lind, E.M., et al. (2014). Herbivores and nutrients control grassland plant diversity via light limitation. Nature, 508, 517.

Borer, E.T., Seabloom, E.W. \& Tilman, D. (2012). Plant diversity controls arthropod biomass and temporal stability. Ecology Letters, 15, 1457-1464.

Brown, J.H., Gillooly, J.F., Allen, A.P., Savage, V.M. \& West, G.B. (2004). Toward a metabolic theory of ecology. Ecology, 85, 1771-1789.

Burdon, J.J., Thrall, P.H., Ericson \& Lars. (2006). The Current and Future Dynamics of Disease in Plant Communities. Annual Review of Phytopathology, 44, 19-39.

Buschmann, H., Keller, M., Porret, N., Dietz, H. \& Edwards, P.J. (2005). The effect of slug grazing on vegetation development and plant species diversity in an experimental grassland. Functional Ecology, 19, 291-298.

Cappelli, S.L., Pichon, N.A., Kempel, A. \& Allan, E. (2019). Sick plants in grassland communities: a growth-defense trade-off is the main driver of fungal pathogen abundance and impact. bioRxiv, 806299.

Chamberlain, S.A., Bronstein, J.L. \& Rudgers, J.A. (2014). How context dependent are species interactions? Ecology Letters, 17, 881-890.

Chase, J.M., Abrams, P.A., Grover, J.P., Diehl, S., Chesson, P., Holt, R.D., et al. (2002). The interaction between predation and competition: a review and synthesis. Ecology Letters, 5, 302-315.

Chase, J.M., Leibold, M.A., Downing, A.L. \& Shurin, J.B. (2000). The effects of productivity, herbivory, and plant species turnover in grassland food webs. Ecology, $81,2485-2497$.

Chesson, P. (2000). Mechanisms of Maintenance of Species Diversity. Annual Review of Ecology and Systematics, 31, 343-366. 
468

469

470

471

472

473

474

475

476

477

478

479

480

481

482

483

484

485

486

487

488

489

490

491

492

493

494

495

496

497

498

499

500

501

502

503

504

505

506

507

508

509

510

511

512

513

514

515

516

517
Coakley, S.M., Scherm, H. \& Chakraborty, S. (1999). Climate change and plant disease management. Annu. Rev. Phytopathol., 37, 399-426.

Coley, P.D., Bryant, J.P. \& Chapin, F. 3rd. (1985). Resource availability and plant antiherbivore defense. Science, 22, 895-899.

Coupe, M.D. \& Cahill Jr, J.F. (2003). Effects of insects on primary production in temperate herbaceous communities: a meta-analysis. Ecological Entomology, 28, 511-521.

Crawley, M.J. (1997). Plant Ecology. Blackwell Publishing, Oxford.

Crawley, M.J., Johnston, A.E., Silvertown, J., Dodd, M., Mazancourt, C. de, Heard, M.S., et al. (2005). Determinants of Species Richness in the Park Grass Experiment. The American Naturalist, 165, 179-192.

Cronin, J.P., Tonsor, S.J. \& Carson, W.P. (2010). A simultaneous test of trophic interaction models: which vegetation characteristic explains herbivore control over plant community mass? Ecology Letters, 13, 202-212.

Dobzhansky, T. (1950). Evolution in the tropics. American Scientist, 38, $209-221$.

Dordas, C. (2008). Role of nutrients in controlling plant diseases in sustainable agriculture. A review. Agronomy for Sustainable Development, 28, 33-46.

Duffy, J.E., Richardson, P.J. \& Canuel, E.A. (2003). Grazer diversity effects on ecosystem functioning in seagrass beds. Ecology Letters, 6, 637-645.

Egerton-Warburton, L.M., Johnson, N.C. \& Allen, E.B. (2007). Mycorrhizal community dynamics following nitrogen fertilization: a cross-site test in five grasslands. Ecological Monographs, 77, 527-544.

Fine, P.V.A., Mesones, I. \& Coley, P.D. (2004). Herbivores Promote Habitat Specialization by Trees in Amazonian Forests. Science, 305, 663.

Ford, A.T., Goheen, J.R., Otieno, T.O., Bidner, L., Isbell, L.A., Palmer, T.M., et al. (2014). Large carnivores make savanna tree communities less thorny. Science, 346, 346.

Fretwell, S. (1987). Food-chain dynamics - the central theory of ecology. OIKOS, 50, 291301.

Galmán, A., Abdala-Roberts, L., Zhang, S., Berny-Mier y Teran, J.C., Rasmann, S. \& Moreira, X. (2018). A global analysis of elevational gradients in leaf herbivory and its underlying drivers: Effects of plant growth form, leaf habit and climatic correlates. Journal of Ecology, 106, 413-421.

Gillespie, M.A.K., Jónsdóttir, I.S., Hodkinson, I.D. \& Cooper, E.J. (2013). Aphid-willow interactions in a high Arctic ecosystem: responses to raised temperature and goose disturbance. Global Change Biology, 19, 3698-3708.

van Grunsven, R.H.A., van der Putten, W.H., Bezemer, T.M. \& Veenendaal, E.M. (2010). Plant-soil feedback of native and range-expanding plant species is insensitive to temperature. Oecologia, 162, 1059-1069.

Gurevitch, J. \& Mengersen, K. (2010). A statistical view of synthesizing patterns of species richness along productivity gradients: devils, forests, and trees. Ecology, 91, 25532560.

Haddad, N.M., Haarstad, J. \& Tilman, D. (2000). The effects of long-term nitrogen loading on grassland insect communities. Oecologia, 124, 73-84.

Haddad, N.M., Tilman, D., Haarstad, J., Ritchie, M. \& Knops, J.M.H. (2001). Contrasting Effects of Plant Richness and Composition on Insect Communities: A Field Experiment. The American Naturalist, 158, 17-35.

Hairston, N.G., Smith, F.E. \& Slobodkin, L.B. (1960). Community structure, population control, and competition. The American Naturalist, 879, 421-425.

Halliday, F.W. \& Rohr, J.R. (2019). Measuring the shape of the biodiversity-disease relationship across systems reveals new findings and key gaps. Nature Communications, 10, 5032. 
Hallmann, C.A., Sorg, M., Jongejans, E., Siepel, H., Hofland, N., Schwan, H., et al. (2017). More than 75 percent decline over 27 years in total flying insect biomass in protected areas. PLOS ONE, 12, e0185809.

Herms, D.A. \& Mattson, W.J. (1992). The Dilemma of Plants: To Grow or Defend. The Quarterly Review of Biology, 67, 283-335.

Hillebrand, H., Gruner, D.S., Borer, E.T., Bracken, M.E.S., Cleland, E.E., Elser, J.J., et al. (2007). Consumer versus resource control of producer diversity depends on ecosystem type and producer community structure. Proc Natl Acad Sci USA, 104, 10904.

HilleRisLambers, J., Adler, P.B., Harpole, W.S., Levine, J.M. \& Mayfield, M.M. (2012). Rethinking Community Assembly through the Lens of Coexistence Theory. Annu. Rev. Ecol. Evol. Syst., 43, 227-248.

Holt, R.D. (1977). Predation, apparent competition, and the structure of prey communities. Theoretical Population Biology, 12, 197-229.

Ishii, R. \& Crawley, M.J. (2011). Herbivore-induced coexistence of competing plant species. Journal of Theoretical Biology, 268, 50-61.

Jablonski, L.M., Wang, X. \& Curtis, P.S. (2002). Plant reproduction under elevated CO2 conditions: a meta-analysis of reports on 79 crop and wild species. New Phytologist, 156, 9-26.

Jactel, H. \& Brockerhoff, E.G. (2007). Tree diversity reduces herbivory by forest insects. Ecology Letters, 10, 835-848.

Jia, S., Wang, X., Yuan, Z., Lin, F., Ye, J., Hao, Z., et al. (2018). Global signal of top-down control of terrestrial plant communities by herbivores. Proc Natl Acad Sci USA, 115, 6237.

Johnson, P.T.J., Preston, D.L., Hoverman, J.T. \& Richgels, K.L.D. (2013). Biodiversity decreases disease through predictable changes in host community competence. Nature, 494, 230-233.

Keane, R.M. \& Crawley, M.J. (2002). Exotic plant invasions and the enemy release hypothesis. Trends in Ecology \& Evolution, 17, 164-170.

Keesing, F., Belden, L.K., Daszak, P., Dobson, A., Harvell, C.D., Holt, R.D., et al. (2010). Impacts of biodiversity on the emergence and transmission of infectious diseases. Nature, 468, 647.

Kempel, A., Razanajatovo, M., Stein, C., Unsicker, S.B., Auge, H., Weisser, W.W., et al. (2015). Herbivore preference drives plant community composition. Ecology, 96, 2923-2934.

Kempel, A., Schädler, M., Chrobock, T., Fischer, M. \& van Kleunen, M. (2011). Tradeoffs associated with constitutive and induced plant resistance against herbivory. Proc Natl Acad Sci USA, 108, 5685.

Kempel, A., Schmidt, A.K., Brandl, R. \& Schädler, M. (2010). Support from the underground: Induced plant resistance depends on arbuscular mycorrhizal fungi. Functional Ecology, 24, 293-300.

Kempel, A., Vincent, H., Prati, D. \& Fischer, M. (2019). Context dependency of biotic interactions and its relation to plant rarity. bioRxiv, 791269.

Korell, L., Lang, B.R., Hensen, I., Auge, H. \& Bruelheide, H. (2017). Interactions count: plant origin, herbivory and disturbance jointly explain seedling recruitment and community structure. Scientific Reports, 7, 8288.

Koricheva, J., Gange, A.C. \& Jones, T. (2009). Effects of mycorrhizal fungi on insect herbivores: a meta-analysis. Ecology, 90, 2088-2097. 
566

567

568

569

570

571

572

573

574

575

576

577

578

579

580

581

582

583

584

585

586

587

588

589

590

591

592

593

594

595

596

597

598

599

600

601

602

603

604

605

606

607

608

609

610

611

612

613

614

Koricheva, J., Mulder, C.P.H., Schmid, B., Joshi, J. \& Huss-Danell, K. (2000). Numerical responses of different trophic groups of invertebrates to manipulations of plant diversity in grasslands. Oecologia, 125, 271-282.

Lake, J.A. \& Wade, R.N. (2009). Plant-pathogen interactions and elevated CO2: morphological changes in favour of pathogens. Journal of Experimental Botany, 60, 3123-3131.

Lavorel, S. \& Grigulis, K. (2012). How fundamental plant functional trait relationships scaleup to trade-offs and synergies in ecosystem services. Journal of Ecology, 100, 128140.

Lemoine, N.P., Doublet, D., Salminen, J.-P., Burkepile, D.E. \& Parker, J.D. (2017). Responses of plant phenology, growth, defense, and reproduction to interactive effects of warming and insect herbivory. Ecology, 98, 1817-1828.

Lind, E.M., Borer, E., Seabloom, E., Adler, P., Bakker, J.D., Blumenthal, D.M., et al. (2013). Life-history constraints in grassland plant species: a growth-defence trade-off is the norm. Ecology Letters, 16, 513-521.

Lind, E.M., La Pierre, K.J., Seabloom, E.W., Alberti, J., Iribarne, O., Firn, J., et al. (2017). Increased grassland arthropod production with mammalian herbivory and eutrophication: a test of mediation pathways. Ecology, 98, 3022-3033.

Liu, Y., Reich, P.B., Li, G. \& Sun, S. (2011). Shifting phenology and abundance under experimental warming alters trophic relationships and plant reproductive capacity. Ecology, 92, 1201-1207.

Loranger, H., Weisser, W.W., Ebeling, A., Eggers, T., De Luca, E., Loranger, J., et al. (2014). Invertebrate herbivory increases along an experimental gradient of grassland plant diversity. Oecologia, 174, 183-193.

Louthan, A.M., Doak, D.F. \& Angert, A.L. (2015). Where and when do species interactions set range limits? Trends in Ecology \& Evolution, 30, 780-792.

Malmström, C.M. \& Raffa, K.F. (2000). Biotic disturbance agents in the boreal forest: considerations for vegetation change models. Global Change Biology, 6, 35-48.

Mangan, S.A., Schnitzer, S.A., Herre, E.A., Mack, K.M.L., Valencia, M.C., Sanchez, E.I., et al. (2010). Negative plant-soil feedback predicts tree-species relative abundance in a tropical forest. Nature, 466, 752.

Maron, J.L., Baer, K.C. \& Angert, A.L. (2014a). Disentangling the drivers of contextdependent plant-animal interactions. Journal of Ecology, 102, 1485-1496.

Maron, J.L., Klironomos, J., Waller, L. \& Callaway, R.M. (2014b). Invasive plants escape from suppressive soil biota at regional scales. Journal of Ecology, 102, 19-27.

Maron, J.L., Marler, M., Klironomos, J.N. \& Cleveland, C.C. (2011). Soil fungal pathogens and the relationship between plant diversity and productivity. Ecology Letters, 14, 3641.

Mitchell, C.E., Reich, P.B., Tilman, D. \& Groth, J.V. (2003). Effects of elevated CO2, nitrogen deposition, and decreased species diversity on foliar fungal plant disease. Global Change Biology, 9, 438-451.

Mitchell, C.E., Tilman, D. \& Groth, J.V. (2002). Effects of grassland plant species diversity, abundance, and composition on foliar fungal disease. Ecology, 83, 1713-1726.

Mordecai, E.A. (2011). Pathogen impacts on plant communities: unifying theory, concepts, and empirical work. Ecological Monographs, 81, 429-441.

Murdoch, W.W. (1969). Switching in General Predators: Experiments on Predator Specificity and Stability of Prey Populations. Ecological Monographs, 39, 335-354.

Myers, J.H. \& Sarfraz, R.M. (2017). Impacts of Insect Herbivores on Plant Populations. Annu. Rev. Entomol., 62, 207-230. 
615 Oksanen, L. \& Oksanen, T. (2000). The logic and realism of the hypothesis of exploitation

616

617

618

619

620

621

622

623

624

625

626

627

628

629

630

631

632

633

634

635

636

637

638

639

640

641

642

643

644

645

646

647

648

649

650

651

652

653

654

655

656

657

658

659

660

661

662

663 ecosystems. American Naturalist, 155, 703-723.

Olff, H. \& Ritchie, M.E. (1998). Effects of herbivores on grassland plant diversity. Trends in Ecology \& Evolution, 13, 261-265.

Pacala, S.W. \& Crawley, M.J. (1992). Herbivores and Plant Diversity. The American Naturalist, 140, 243-260.

Petermann, J.S., Fergus, A.J.F., Turnbull, L.A. \& Schmid, B. (2008). Janzen-Connell Effects Are Widespread and Strong Enough to Maintain Diversity in Grasslands. Ecology, 89, 2399-2406.

Pimentel, D. (1961). Species Diversity and Insect Population Outbreaks. Annals of the Entomological Society of America, 54, 76-86.

Post, E. \& Pedersen, C. (2008). Opposing plant community responses to warming with and without herbivores. Proc Natl Acad Sci USA, 105, 12353.

Pozo, M.J. \& Azcón-Aguilar, C. (2007). Unraveling mycorrhiza-induced resistance. Current Opinion in Plant Biology, 10, 393-398.

Proulx, M. \& Mazumder, A. (1998). Reversal of grazing impact on plant species richness in nutrient-poor vs. nutrient-rich ecosystems. Ecology, 79, 2581-2592.

Rasmann, S., Pellissier, L., Defossez, E., Jactel, H. \& Kunstler, G. (2014). Climate-driven change in plant-insect interactions along elevation gradients. Functional Ecology, 28, 46-54.

Richardson, S.J., Press, M.C., Parsons, A.N. \& Hartley, S.E. (2002). How do nutrients and warming impact on plant communities and their insect herbivores? A 9-year study from a sub-Arctic heath. Journal of Ecology, 90, 544-556.

Robinson, E.A., Ryan, G.D. \& Newman, J.A. (2012). A meta-analytical review of the effects of elevated $\mathrm{CO} 2$ on plant-arthropod interactions highlights the importance of interacting environmental and biological variables. New Phytologist, 194, 321-336.

Root, R.B. (1973). Organization of a Plant-Arthropod Association in Simple and Diverse Habitats: The Fauna of Collards (Brassica Oleracea). Ecological Monographs, 43, 95-124.

Rottstock, T., Joshi, J., Kummer, V. \& Fischer, M. (2014). Higher plant diversity promotes higher diversity of fungal pathogens, while it decreases pathogen infection per plant. Ecology, 95, 1907-1917.

Roy, B.A., Güsewell, S. \& Harte, J. (2004). Response of plant pathogens and herbivores to a warming experiment. Ecology, 85, 2570-2581.

Sala, O.E., Stuart Chapin, F., III, Armesto, J.J., Berlow, E., Bloomfield, J., et al. (2000). Global Biodiversity Scenarios for the Year 2100. Science, 287, 1770.

Sardans, J., Rivas-Ubach, A. \& Peñuelas, J. (2012). The C:N:P stoichiometry of organisms and ecosystems in a changing world: A review and perspectives. Perspectives in Plant Ecology, Evolution and Systematics, 14, 33-47.

Schädler, M., Jung, G., Auge, H. \& Brandl, R. (2003). Does the Fretwell-Oksanen model apply to invertebrates? Oikos, 100, 203-207.

Schemske, D.W., Mittelbach, G.G., Cornell, H.V., Sobel, J.M. \& Roy, K. (2009). Is There a Latitudinal Gradient in the Importance of Biotic Interactions? Annu. Rev. Ecol. Evol. Syst., 40, 245-269.

Scherber, C., Eisenhauer, N., Weisser, W.W., Schmid, B., Voigt, W., Fischer, M., et al. (2010). Bottom-up effects of plant diversity on multitrophic interactions in a biodiversity experiment. Nature, 468, 553.

Schnitzer, S.A. \& Klironomos, J. (2011). Soil microbes regulate ecosystem productivity and maintain species diversity. Plant signaling \& behavior, 6, 1240-1243. 
664

665

666

667

668

669

670

671

672

673

674

675

676

677

678

679

680

681

682

683

684

685

686

687

688

689

690

691

692

693

694

695

696

697

698

699

700

701

702

703

704

705

706

707

708

709

Schnitzer, S.A., Klironomos, J.N., HilleRisLambers, J., Kinkel, L.L., Reich, P.B., Xiao, K., et al. (2011). Soil microbes drive the classic plant diversity-productivity pattern. Ecology, 92, 296-303.

Schweiger, O., Heikkinen, R.K., Harpke, A., Hickler, T., Klotz, S., Kudrna, O., et al. (2012). Increasing range mismatching of interacting species under global change is related to their ecological characteristics. Global Ecology and Biogeography, 21, 88-99.

Seabloom, E.W., Borer, E.T. \& Kinkel, L.L. (2018). No evidence for trade-offs in plant responses to consumer food web manipulations. Ecology, 99, 1953-1963.

Seabloom, E.W., Kinkel, L., Borer, E.T., Hautier, Y., Montgomery, R.A. \& Tilman, D. (2017). Food webs obscure the strength of plant diversity effects on primary productivity. Ecology Letters, 20, 505-512.

Seibold, S., Gossner, M.M., Simons, N.K., Blüthgen, N., Müller, J., Ambarlı, D., et al. (2019). Arthropod decline in grasslands and forests is associated with landscape-level drivers. Nature, 574, 671-674.

Stein, C., Unsicker, S.B., Kahmen, A., Wagner, M., Audorff, V., Auge, H., et al. (2010). Impact of invertebrate herbivory in grasslands depends on plant species diversity. Ecology, 91, 1639-1650.

Stevens, C.J., Dise, N.B., Mountford, J.O. \& Gowing, D.J. (2004). Impact of Nitrogen Deposition on the Species Richness of Grasslands. Science, 303, 1876.

Stiling, P. \& Cornelissen, T. (2007). How does elevated carbon dioxide (CO2) affect plantherbivore interactions? A field experiment and meta-analysis of $\mathrm{CO} 2$-mediated changes on plant chemistry and herbivore performance. Global Change Biology, 13, 1823-1842.

Sundqvist, M.K., Sanders, N.J. \& Wardle, D.A. (2013). Community and Ecosystem Responses to Elevational Gradients: Processes, Mechanisms, and Insights for Global Change. Annu. Rev. Ecol. Evol. Syst., 44, 261-280.

Suttle, K.B., Thomsen, M.A. \& Power, M.E. (2007). Species Interactions Reverse Grassland Responses to Changing Climate. Science, 315, 640.

Terborgh, J.W. (2015). Toward a trophic theory of species diversity. Proc Natl Acad Sci USA, 112, 11415.

Thompson, G.B. \& Drake, B.G. (1994). Insects and fungi on a C3 sedge and a C4 grass exposed to elevated atmospheric $\mathrm{CO} 2$ concentrations in open-top chambers in the field. Plant, Cell \& Environment, 17, 1161-1167.

Tylianakis, J.M., Didham, R.K., Bascompte, J. \& Wardle, D.A. (2008). Global change and species interactions in terrestrial ecosystems. Ecology Letters, 11, 1351-1363.

Van Der Heijden, M.G.A., Bardgett, R.D. \& Van Straalen, N.M. (2008). The unseen majority: soil microbes as drivers of plant diversity and productivity in terrestrial ecosystems. Ecology Letters, 11, 296-310.

Wardle, D.A., Jonsson, M., Bansal, S., Bardgett, R.D., Gundale, M.J. \& Metcalfe, D.B. (2012). Linking vegetation change, carbon sequestration and biodiversity: insights from island ecosystems in a long-term natural experiment. Journal of Ecology, 100, $16-30$.

Zuppinger-Dingley, D., Schmid, B., Chen, Y., Brandl, H., van der Heijden, M.G.A. \& Joshi, J. (2011). In their native range, invasive plants are held in check by negative soilfeedbacks. Ecosphere, 2, art54. 